\title{
PERÍODO ANTERIOR A INTERFERÊNCIA DE PLANTAS DANINHAS EM SOJA TRANSGÊNICA
}

\section{PERIOD BEFORE WEED INTERFERENCE IN TRANSGENIC SOYBEAN}

\author{
José Guilherme Rehder BENEDETTI ${ }^{1}$ \\ Larissa PEREIRA ${ }^{1}$ \\ Pedro Luís da Costa Aguiar ALVES ${ }^{2}$ \\ Micheli Satomi YAMAUTI ${ }^{3}$
}

\begin{abstract}
RESUMO
O presente trabalho foi conduzido com o objetivo de se determinar o período anterior à interferência das plantas daninhas com a cultura da soja, cv. Monsoy 7908 RR plantada no sistema convencional. Os períodos de convivência estudados foram: $0,10,15,20,30,40,50,60$ e 118 dias após a emergência, totalizando 10 tratamentos, que foram dispostos em blocos casualizados, com quatro repetições. A comunidade infestante foi composta por 20 espécies, com Alternanthera tenella, Digitaria nuda e Eleusine indica se destacando das demais. A cultura conviveu com a comunidade infestante até 25 dias após o plantio, sem interferir significativamente na produtividade. A interferência das plantas daninhas diminuiu 0 potencial produtivo da soja em $30 \%$.
\end{abstract}

Palavras-chave: competição; Glycine max; período de controle.

\section{ABSTRACT}

The experiment was carried out to determine the period before weed interference in soybean cv. Monsoy $7908 \mathrm{RR}$ in a conventional till system. The periods of weed control studied were: $0,10,15,20,30,40,50,60$ and 118 days after planting, totaling 10 treatments, arranged in a randomized block design, with four replications. The weed community comprised twenty species. The species Alternanthera tenella, Digitaria nuda and Eleusine indica were the most prominent. Soybean grew along with the weed community up to 25 days after planting, without significant yield loss. Weed interference during the full crop cycle reduced, in average, $30 \%$ of potential productivity.

Key-words: competition; Glycine max; control period.

\footnotetext{
${ }^{1}$ Engenheiro Agrônomo, Departamento de Biologia Aplicada a Agropecuária, Faculdade de Ciências Agrárias e Veterinárias, Universidade Estadual Paulista Júlio de Mesquita Filho (UNESP), Campus Jaboticabal, Jaboticabal - SP, Brasil. E-mail: kikobenedetti@hotmail.com; ala_fcav@hotmail.com.

${ }^{2}$ Professor Dr., Departamento de Biologia Aplicada a Agropecuária, Faculdade de Ciências Agrárias e Veterinárias, Universidade Estadual Paulista Júlio de Mesquita Filho, Campus Jaboticabal. Via de acesso Prof. Dr. Paulo D. Castellane, s/n. Zona Rural. CEP 14884-900. Jaboticabal - SP, Brasil. Autor para correspondência. E-mail: plalves@fcav.unesp.br.

${ }^{3}$ Engenheira Agrônoma, Mestre em Produção Vegetal, Departamento de Biologia Aplicada a Agropecuária, Faculdade de Ciências Agrárias e Veterinárias, Universidade Estadual Paulista Júlio de Mesquita Filho, Campus Jaboticabal. Jaboticabal - SP, Brasil. E-mail: micheliyamauti@yahoo.com.br.
} 
BENEDETTI, J.G.R. et al. Período anterior à interferência de plantas daninhas...

\section{INTRODUÇÃO}

A soja (Glycine max (L.) Merrill) constituise na mais importante oleaginosa cultivada no mundo. O Brasil é o segundo maior produtor e um dos principais exportadores de grãos de soja. A partir da década de 90, o Centro-Oeste tornou-se a principal região produtora, sendo responsável por aproximadamente $45 \%$ do total da produção brasileira na safra 2007/2008 (Agrianual, 2008).

Com a introdução de variedades transgênicas, resistentes ao herbicida glyphosate, houve ampliação da área de soja plantada e maior facilidade no controle da maioria das espécies de plantas daninhas infestantes. O glyphosate é aplicado em pós-emergência da cultura, absorvido e translocado sem afetar seu crescimento, promovendo eficiente controle das plantas daninhas nos estádios em que a competição seria extremamente negativa para a cultura (Santos et al., 2007), representando uma nova alternativa de controle em função da eficiência e viabilidade econômica, características essenciais no conceito de praticabilidade (Gazziero et al., 2004). A utilização de glyphosate nessa cultura diminuiu o custo do controle de plantas daninhas (Monquero, 2005), porém está causando seleção de espécies tolerantes e resistentes a esse herbicida (Vargas et al., 2005; Ferreira et al., 2006).

Os efeitos da interferência são irreversíveis, não havendo recuperação do desenvolvimento ou da produtividade após retirada do estresse causado pela presença das plantas daninhas (Koslowski et al., 2002). Os efeitos decorrentes dessa interferência sobre características de plantas cultivadas podem comprometer o desenvolvimento de estruturas reprodutivas e afetar os componentes da produtividade de grãos (Lamego et al., 2004). O grau de interferência causado pelas plantas daninhas na cultura depende da época e duração do período de convivência (Pitelli, 1985).

As determinações dos períodos de convivência tolerados por uma cultura com as plantas daninhas são obtidas estudando-se os períodos críticos de interferência (Pitelli \& Durigan, 1984). Em termos de manejo de plantas daninhas, o período anterior a interferência (PAI) torna-se um dos períodos de maior importância do ciclo cultural, a partir do qual a produtividade é significativamente afetada (Meschede et al., 2004). Os períodos de interferência na soja tem sido alvo de várias pesquisas realizadas por Durigan (1983), Spadotto et al. (1994), Carvalho \& Velini (2001), Meschede et al. (2002), Meschede et al. (2004), Constantin et al. (2007) e Nepomuceno et al. (2007). Entretanto, poucas informações sobre a interferência sofrida pelas principais cultivares de soja $R R$ em relação às plantas daninhas tem sido geradas.

O objetivo do trabalho foi determinar o período em que a cultura da soja, cv. Monsoy 7908 $\mathrm{RR}$, pode conviver com as plantas daninhas sem que ocorra interferência negativa em sua produção final.

\section{MATERIAL E MÉTODOS}

Esta pesquisa constou de um experimento, instalado e conduzido em área experimental pertencente à Faculdade de Ciências Agrárias e Veterinárias da Universidade Estadual Paulista UNESP, localizada no município de Jaboticabal $\mathrm{SP}$, que se encontra à latitude de $21^{\circ} 15^{\prime} 22^{\prime \prime S}$, longitude de $48^{\circ} 18^{\prime} 58^{\prime \prime} \mathrm{W}$ e altitude de $595 \mathrm{~m}$. O solo da área experimental é classificado como Latossolo Vermelho eutrófico típico textura argilosa A moderado, apresentando topografia suavemente ondulada e condições de boa drenagem (Andrioli \& Centurion, 1999). O clima da região de Jaboticabal, baseado na classificação internacional de Köeppen, é do tipo Cwa. Na época das águas predominam as chuvas de verão, com inverno relativamente seco.

O experimento foi instalado no sistema de semeadura convencional no mês de dezembro no ano agrícola 2007/2008. A cultivar utilizada foi a Monsoy 7908 RR, semeada no espaçamento de $0,45 \mathrm{~m}$ entre linhas, depositando-se 20 sementes por metro linear, previamente tratadas com fungicida Thiram (300 $\mathrm{cm}^{3} 100 \mathrm{~kg}^{-1}$ de sementes). Realizou-se a adubação no sulco de plantio com $300 \mathrm{~kg} \mathrm{ha}^{-1}$ de NPK da formulação 8-20-20.

Cada unidade experimental foi constituída de sete linhas de plantas (espaçadas $0,45 \mathrm{~m}$ entre si) com $10 \mathrm{~m}$ de comprimento, totalizando $31,5 \mathrm{~m}^{2}$. A área útil para as avaliações compreendeu as três linhas centrais.

Os tratamentos consistiram em períodos de convivência da cultura com as plantas daninhas. A cultura foi mantida sob competição das plantas daninhas por períodos iniciais crescentes desde a emergência da soja por 10, 15, 20, 30, 40, 50, 60 e 118 dias (todo ciclo da cultura). Após o término de cada período inicial de convivência, foi realizado o controle das plantas daninhas nas parcelas correspondentes, que foram mantidas no limpo até a colheita, por meio de aplicação de herbicida glyphosate, utilizando dose de $960 \mathrm{~g}^{\text {ha }}{ }^{-1}$ de equivalente ácido, com volume de calda correspondente à $200 \mathrm{dm}^{3} \mathrm{ha}^{-1}$. Duas testemunhas foram mantidas no limpo, uma com controle das plantas daninhas realizada com a aplicação de glyphosate e outra por meio de capinas manuais.

O delineamento experimental utilizado foi o de blocos casualizados, com 10 tratamentos em quatro repetições. Ao término de cada período de convivência das plantas daninhas com a cultura foi realizado levantamento da comunidade infestante. A área total amostrada em cada parcela, foi de 0,5 $\mathrm{m}^{2}$, composta por duas sub amostras de $0,25 \mathrm{~m}^{2}$ $(0,5 \mathrm{~m} \times 0,5 \mathrm{~m})$, colhidas aleatoriamente na área útil da parcela. As partes aéreas das plantas daninhas encontradas nas duas sub-amostras foram coletadas e separadas, por espécie, determinandose os valores de densidade e de massa seca de cada população. A massa seca da parte aérea das plantas daninhas foi obtida pela secagem em estufa com ventilação forçada de ar a $70{ }^{\circ} \mathrm{C}$, até atingir massa constante.

Os dados de densidade e massa seca da 
comunidade infestante foram extrapolados para número de plantas e gramas de massa seca por metro quadrado, respectivamente. Os dados de matéria seca foram submetidos à análise de regressão, obtendo ajuste exponencial (MS = $M S i^{*} \exp (-x / t 1)$. Com os dados obtidos em cada amostragem foi realizada a análise fitossociológica da comunidade infestante, segundo procedimento descrito por Mueller-Dombois \& Ellemberg (1974), sendo determinadas, para cada espécie, a freqüência relativa, a densidade relativa, a dominância relativa e a importância relativa (IR).

Por ocasião da colheita, foram feitas determinações da produtividade e de peso de 100 grãos. As análises dos dados de produtividade foram processadas separadamente, dentro de cada grupo (períodos iniciais de convivência ou de controle da plantas daninhas). Os resultados de produtividade foram submetidos à análise de regressão pelo modelo sigmoidal de Boltzman, conforme utilizado por Kuva et al. (2001).

$$
Y=A_{2}+\left[\left\{A_{1}-A_{2}\right\} /\left\{1+e^{((x-x o) / d x)}\right\}\right]
$$

Onde: $Y$ é a produção de soja em kg ha-1, obtida conforme os períodos de convivência; $X$, o limite superior do período de convivência ou controle considerado; $A_{1}$, a produção máxima obtida nas parcelas mantidas no limpo durante todo o ciclo; $A_{2}$, a produção mínima estimada decorrente das parcelas mantidas no mato durante todo o ciclo; $X_{\mathrm{o}}$, o período superior do período de convivência ou controle, que corresponde ao valor intermediário entre a produção máxima e a mínima; e $d x$, o parâmetro que indica a velocidade de perda ou ganho de produção (tangente no ponto $X_{\circ}$ ).

Com base na equação de regressão foi determinado o período anterior de interferência das plantas daninhas (PAI) para o nível arbitrário de tolerância de $5 \%$ de redução na produtividade, em relação ao tratamento mantido na ausência das plantas daninhas.

\section{RESULTADOS E DISCUSSÃO}

Pelos levantamentos feitos na comunidade infestante da cultura, durante a condução do experimento, de acordo com a família a qual pertencem, nomes científicos, nomes populares e código internacional, segundo a International Weed Society, verificou-se que as plantas daninhas que ocorreram na área experimental foram: Amaranthaceae: Alternanthera tenella Colla (apagafogo) ALRTE, Amaranthus deflexus L. (carururasteiro) AMADE e Amaranthus viridis L. (caruru-demancha) AMAVI; Asteraceae (Compositae): Acanthospermum hispidum DC. (carrapicho-decarneiro) ACNHI, Bidens pilosa L. (picão-preto) BIDPI, Emilia sonchifolia DC. (falsa-serralha) EMISO e Xanthium strumarium L. (carrapichão) XANSI; Caesalpiniaceae (Leguminosae): Senna obtusifolia (L.) Irwin \& Barneby (fedegoso) CASOB; Cyperaceae: Cyperus rotundus L. (tiririca) CYPRO; Commelinaceae: Commelina benghalensis L. (trapoeraba) COMBE; Convolvulaceae: Ipomoea grandifolia (Dammer) O' Don (corda-de-viola)
IAOGR; Fabaceae (Leguminosae): Indigofera hirsuta L. (anileira) INDHI e Desmodium tortuosum (Sw.)DC. (desmódio) DEDTO; Malvaceae: Sida rhombifolia L. (guanxuma) SIDRH; Poaceae (Gramineae): Digitaria nuda Schumach. (capimcolchão) DIGNU, Cenchus echinatus L. (capimcarrapicho) CCHEC, Panicum maximum Jacq (capim-colonião) PANMA e Eleusine indica (L.) Gaertn (capim-pé-de-galinha) ELEIN; Portulacaceae: Portulaca oleracea L. (beldroega) POROL; Rubiaceae:-Richardia Brasiliensis Gomes (poaia-branca) RCHBR.

A comunidade infestante foi composta por vinte espécies de plantas daninhas, das quais $65 \%$ foram de dicotiledôneas e $35 \%$ de monocotiledôneas. Dentre elas, destacaram-se três espécies: Alternanthera tenella (ALRTE), Digitaria nuda (DIGNU) e Eleusine indica (ELEIN). Com relação às famílias encontradas na comunidade infestante, onze no total, prevaleceram três delas: Poaceae e Asteraceae com 4 espécies e Amaranthaceae com 3 espécies.

Analisando-se a densidade da comunidade infestante em resposta aos períodos de convivência (Figura 1), verificou-se que aos 15 dias após a emergência (DAE) da cultura a densidade da comunidade infestante atingiu valor máximo (422 plantas $\mathrm{m}^{-2}$ ), com um segundo fluxo de emergência aos $60 \mathrm{DAE}$, com densidade de 265 plantas $\mathrm{m}^{-2}$, decrescendo após esse período e atingindo 59 plantas $\mathrm{m}^{-2}$ aos 120 DAE. A não-uniformidade no fluxo de emergência é característica de plantas daninhas (Radosevich \& Holt, 1984). A massa seca da parte aérea apresentou crescimento exponencial com o decorrer do tempo e foi máxima aos 120 DAE (colheita), atingindo $1.588 \mathrm{~g} \mathrm{~m}^{-2}$ (Figura 2).

De acordo com Radosevich \& Holt (1984), à medida que aumenta a densidade e o desenvolvimento das plantas daninhas, especialmente daquelas que germinaram e emergiram no início do ciclo de uma cultura, como a da soja, intensifica-se a competição interespecífica e intra-específica, de modo que as plantas daninhas mais altas e desenvolvidas tornam-se dominantes, ao passo que as menores são suprimidas e até chegam a morrer. Esse comportamento de uma comunidade infestante justifica a redução da densidade das plantas com o aumento da massa seca nos períodos de desenvolvimento finais da soja.

Analisando-se as espécies de plantas daninhas observou-se que houve maior importância relativa (IR) de $A$. tenella durante todo o ciclo (Figura 3). A maior IR de A. tenella deve-se basicamente a sua maior densidade relativa $\mathrm{e}$ acúmulo de massa seca quando comparado às demais espécies. Dos 40 DAE até os 60 DAE, a IR relativa de $A$. tenella diminuiu por causa da competição intra e inter específica, dando chance para outras plantas mais rústicas terem um aumento na IR, em virtude do seu acúmulo de matéria seca. Dos 60 dias até a colheita, $A$. tenella voltou a aumentar IR de forma crescente, devido a sua maior densidade relativa e acúmulo de matéria 
BENEDETTI, J.G.R. et al. Período anterior à interferência de plantas daninhas...

seca, sendo a mais importante na colheita. E. indica teve uma grande importância relativa de início, que foi reduzindo até $20 \mathrm{DAE}$, sendo que após esse período até os $30 \mathrm{DAE}$ ela teve sua importância aumentada consideravelmente, devido principalmente à queda de IR da $A$. tenella. Após esse período (30 DAE), foi a planta de menor IR por apresentar menor dominância relativa e chegando a $0 \%$ de IR no período da colheita. D. nuda apresentou uma importância regular durante toda o ciclo, sendo a segunda espécie com maior IR na colheita, provavelmente devido ao seu porte mais alto, conseguindo superar o fechamento da cultura, ao contrário do que aconteceu com o E. indica. Todas as outras plantas juntas apresentaram grande aumento de importância relativa após 40 DAE.

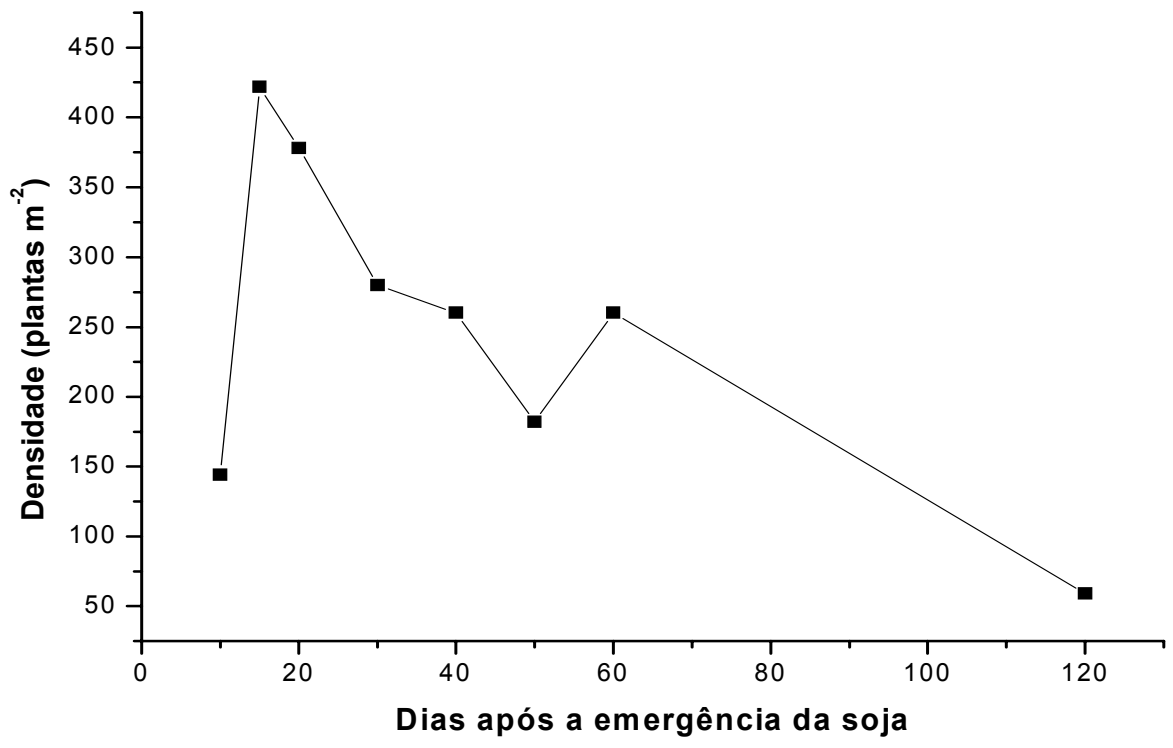

FIGURA 1 - Densidade das plantas daninhas em função dos dias após a emergência da cultura da soja 'Monsoy 7908 RR'.

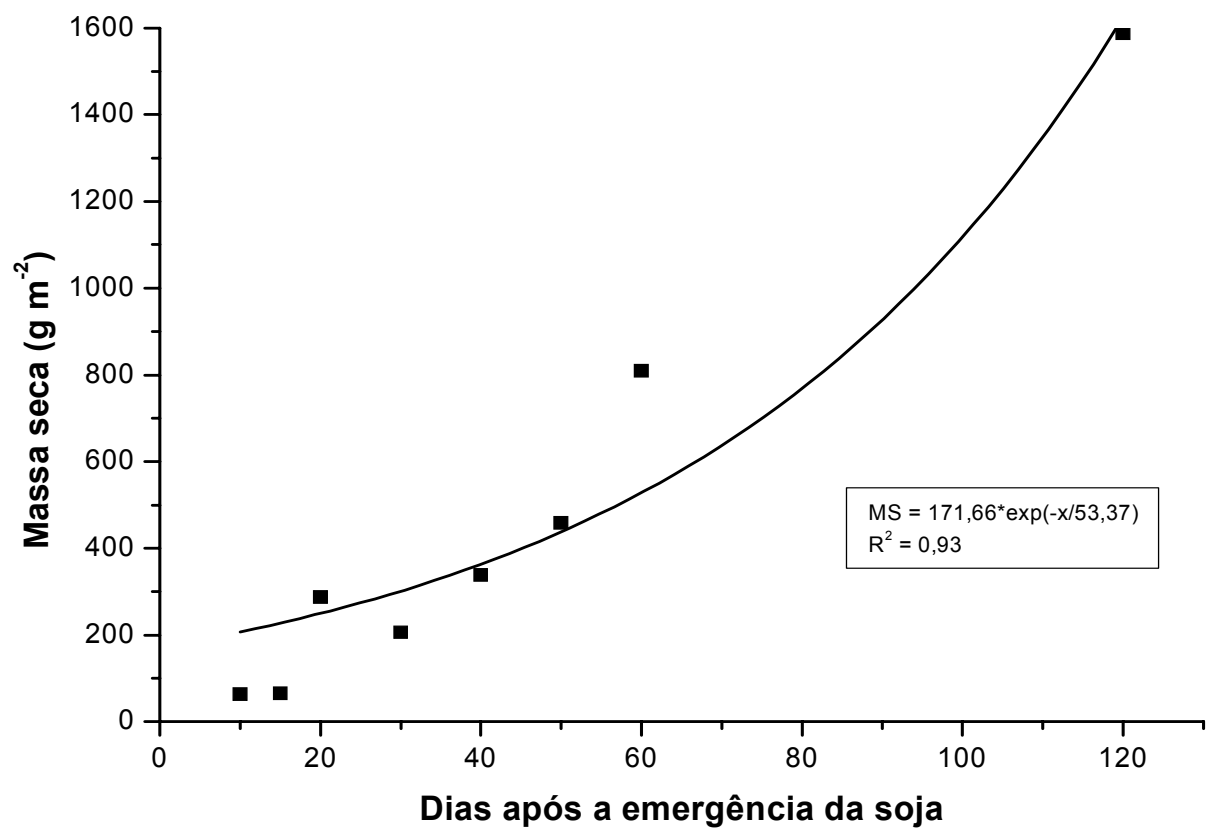

FIGURA 2 - Massa seca das plantas daninhas em função dos dias após a emergência da cultura da soja 'Monsoy 7908 RR'. 


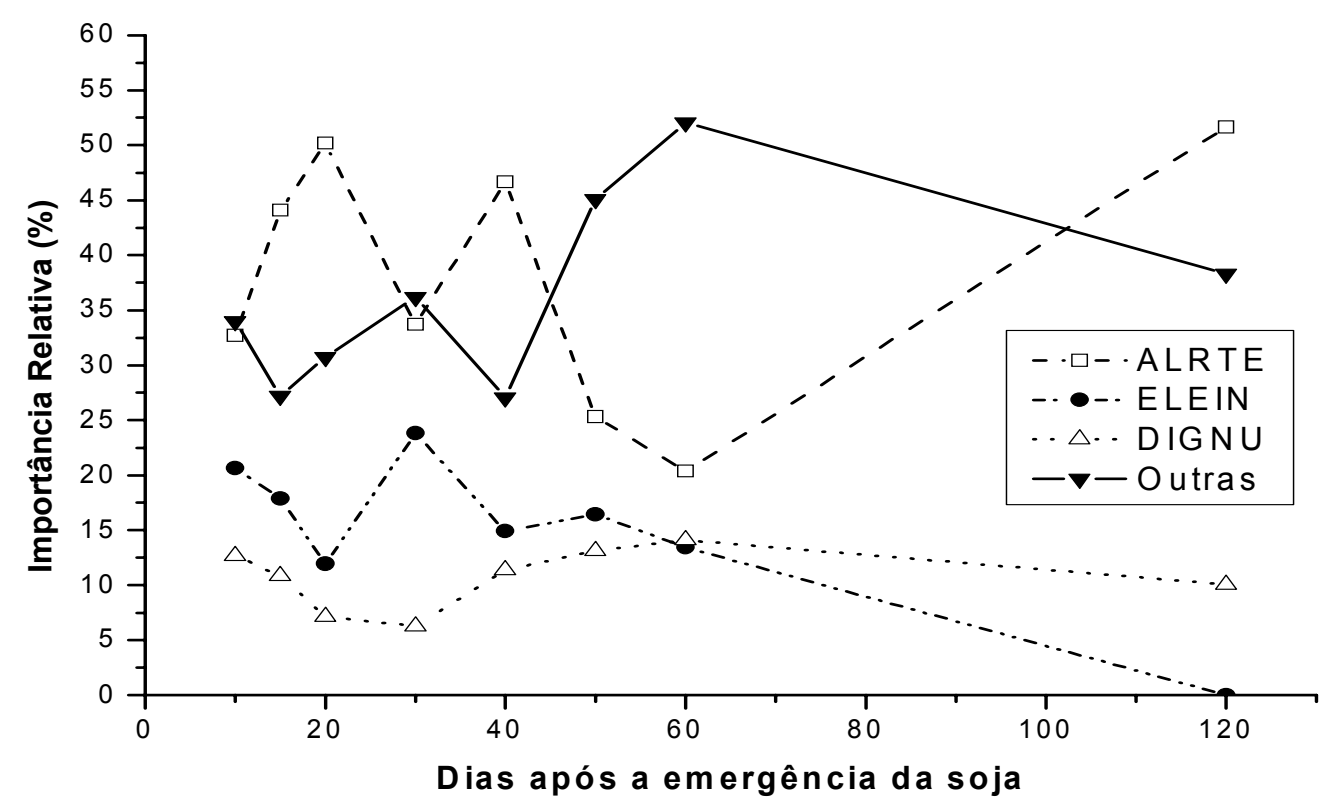

FIGURA 3 - Importância Relativa de Alternanthera tenella (ALRTE), Eleusine indica (ELEIN), Digitaria nuda (DIGNU) e demais espécies, em função dos dias após a emergência da soja 'Monsoy 7908 RR'.

Comparando-se a produção obtida na ausência total das plantas daninhas (testemunha no limpo - glyphosate) com a obtida na presença dessas durante todo o ciclo (testemunha no mato), verificou-se uma redução de $19,9 \%$ na produção de grãos, sendo a produtividade máxima alcançada de $3399,2 \mathrm{~kg} \mathrm{ha}^{-1}$ e a mínima de $2722,2 \mathrm{~kg} \mathrm{ha}^{-1}$ (Tabela 1). Se comparada essa testemunha no limpo com o tratamento onde a cultura conviveu 60 dias com as plantas daninhas, a diferença foi ainda maior, chegando a uma perda de $30,1 \%$, devido a alta infestação de carrapichão (Xanthium strumarium) nas parcelas, que é uma planta mais agressiva, com porte alto e parte aérea fibrosa causa muita perda na colheita. Por ser uma planta daninha de ciclo longo, ela começou a ter um maior desenvolvimento a partir de 50 dias após o plantio, tendo sua maior interferência nas parcelas do tratamento com convivência de 60 dias. Não se constatou diferença entre a produtividade obtida entre as duas testemunhas mantidas no limpo (capinada e com aplicação de glyphosate).

Tolerando-se redução de $5 \%$ na produtividade (Figura 4), a cultura da soja passou a ser afetada negativamente pela convivência com as plantas daninhas a partir de 25 DAE (PAI). Provavelmente, tal efeito se deve inicialmente a $A$. tenella e a $E$. indica, que apresentaram elevada IR aos $25 \mathrm{DAE}$, e o efeito posterior deve-se principalmente a $A$. tenella, que se destacou pela IR.

TABELA 1 - Efeito dos diferentes períodos de convivência com as plantas daninhas sobre a produtividade e massa de 100 grãos de soja 'Monsoy 7908 RR'.

\begin{tabular}{|c|c|c|}
\hline Tratamentos & Massa de 100 grãos (g) & Produtividade $\left(\mathrm{kg} \mathrm{ha}^{-1}\right)$ \\
\hline Test. capinada & $18,6 a^{*}$ & $3249,8 a b$ \\
\hline Test. aplicada & $19,3 \mathrm{a}$ & 3399,2 a \\
\hline 10 dias no mato & $18,9 \mathrm{a}$ & 3374,8 a \\
\hline 15 dias no mato & $18,8 \mathrm{a}$ & $3205,9 a b$ \\
\hline 20 dias no mato & $19,5 \mathrm{a}$ & $3256,7 \mathrm{ab}$ \\
\hline 30 dias no mato & $19,6 \mathrm{a}$ & $3026,9 \mathrm{abc}$ \\
\hline 40 dias no mato & $18,7 \mathrm{a}$ & $2619,5 \mathrm{~cd}$ \\
\hline 50 dias no mato & $18,9 \mathrm{a}$ & 2882,4 bc \\
\hline 60 dias no mato & $18,2 \mathrm{a}$ & $2375,7 \mathrm{~d}$ \\
\hline 120 dias no mato & $19,1 \mathrm{a}$ & $2722,2 \mathrm{~cd}$ \\
\hline $\mathrm{F}_{\text {TRAT. }}$ & $1,38^{\mathrm{NS}}$ & $14,55^{\star *}$ \\
\hline $\mathrm{F}_{\mathrm{BL}}$ & $0,77^{\mathrm{NS}}$ & $0,83^{N S}$ \\
\hline DMS & 1,8 & 445 \\
\hline $\mathrm{CV}(\%)$ & 3,84 & 6,08 \\
\hline
\end{tabular}

*Medias seguidas por mesma letra, na coluna, não diferem entre si ao nível de $5 \%$ pelo teste de Tukey

Scientia Agraria, Curitiba, v.10, n.4, p.289-295, July/Aug. 2009. 
BENEDETTI, J.G.R. et al. Período anterior à interferência de plantas daninhas...

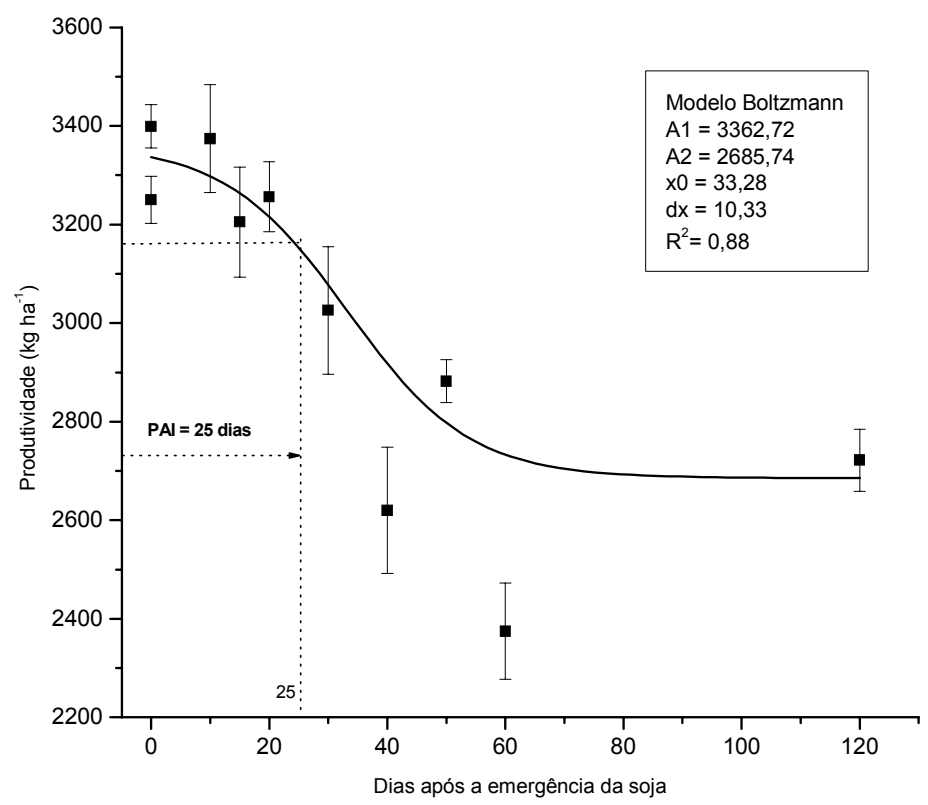

FIGURA 4 - Produção da soja 'Monsoy 7908 RR', em resposta aos períodos de controle e de convivência com as plantas daninhas, considerando-se uma perda de $5 \%$ na produtividade.

\section{CONCLUSÕES}

Assim, no sistema como foi conduzido o experimento, com predominância na comunidade infestante de $A$. tenella (apaga-fogo), E. indica (capim-pé-de-galinha) e D. nuda (capim-colchão), a cultivar de soja Monsoy 7908 RR pôde conviver com essa comunidade até 25 dias após sua emergência (PAI) sem sofrer interferências significativas na produção.

\section{REFERÊNCIAS}

1. AGRIANUAL. Anuário da agricultura brasileira. São Paulo: FNP Consultoria \& Comércio, 2008. p. 443-473.

2. ANDRIOLI, I.; CENTURION, J. F. Levantamento detalhado dos solos da Faculdade de Ciências Agrárias e Veterinária de Jaboticabal. In: CONGRESSO BRASILEIRO DE CIÊNCIA DO SOLO, 27., Brasília, 1999. Anais... Brasília: Sociedade Brasileira de Ciência do Solo, 1999. 32 f. 3 CD-ROM.

3. CARVALHO, F. T.; VELINI, E. D. Períodos de interferência de plantas daninhas na cultura da soja. I - Cultivar IAC-11. Planta Daninha, v. 19, n. 3, p. 317-322, 2001.

4. CONSTANTIN, J. et al. Estimativa do período que antecede a interferência de plantas daninhas na cultura da soja, var. Coodetec 202, por meio de testemunhas duplas. Planta Daninha, v. 25, n. 2, p. 231-237, 2007.

5. DURIGAN, J. C. et al. Período de matocompetição na cultura da soja (Glycine max (L.) Merrill), cultivares Santa Rosa e IAC 2. 1 - Efeitos sobre os parâmetros de produção. Planta Daninha, v. 6, n. 2, p. 86-100, 1983.

6. FERREIRA, E. A. et al. Glyphosate no controle de biótipos de azevém e impacto na microbiota do solo. Planta Daninha, v. 24, n. 3, p. 573-578, 2006.

7. GAZZIERO, D. L. P. et al. Variabilidade no grau de resistência de capim-marmelada (Brachiaria plantaginea) aos herbicidas clethodim, tepraloxydim e sethoxydim. Planta Daninha, v. 22, n. 3, p. 397-402, 2004

8. KOSLOWSKI, L. A. et al. Interferência das plantas daninhas na cultura do feijoeiro comum em sistema de semeadura direta. Planta Daninha, v. 20, n. 2, p. 213-220, 2002

9. KUVA, M. A. et al. Períodos de interferência das plantas daninhas na cultura da cana-de-açúcar. II - Capim-braquiária (Brachiaria decumbens). Planta Daninha, v. 19, n. 3, p. 323-330, 2001.

10. LAMEGO, F. P. et al. Tolerância à interferência de plantas competidoras e habilidade de supressão por genótipos de soja - II. Resposta de variáveis de produtividade. Planta Daninha, v. 22, n. 4, p. 491-498, 2004.

11. MESCHEDE, D. K. et al. Período crítico de interferência de Euphorbia heterophylla na cultura da soja sob baixa densidade de semeadura. Planta Daninha, v. 20, n. 3, p. 381-387, 2002.

12. MESCHEDE, D. K. et al. Período anterior a interferência de plantas daninhas em soja: estudo de caso com baixo estande e testemunhas duplas. Planta Daninha, v. 22, n. 2, p. 239-246, 2004.

13. MONQUERO, P. A. Plantas transgênicas resistentes aos herbicidas: situação e perspectivas. Bragantia, v. 64 , n. 4 , p. 517-531, 2005

14. MUELLER-DOMBOIS, D.; ELLEMBERG, H. Aims and methods of vegetation ecology. New York: John Willey \& Sons, 1974. $547 \mathrm{p}$

15. NEPOMUCENO, M. et al. Períodos de interferência das plantas daninhas na cultura da soja nos sistemas de semeadura direta e convencional. Planta Daninha, v. 25, n. 1, p. 43-50, 2007. 
BENEDETTI, J.G.R. et al. Período anterior à interferência de plantas daninhas...

16. PITELLI, R. A.; DURIGAN, J. C. Terminologia para períodos de controle e de convivência das plantas daninhas em culturas anuais e bianuais. In: CONGRESSO BRASILEIRO DE HERBICIDAS E PLANTAS DANINHAS, 15., 1984, Belo Horizonte. Resumos... Belo Horizonte: SBHED, 1984. p. 37.

17. PITELLI, R. A. Interferência de plantas daninhas em culturas agrícolas. Informe Agropecuário, v. 11, n. 129, p. 16-27, 1985.

18. RADOSEVICH, S. R.; HOLT, J. S. Weed ecology: implications for vegetation management. New York: John Wiley \& Sons, 1984. 263 p.

19. SANTOS, J. B. et al. Efeito de formulações na absorção e translocação do glyphosate em soja transgênica. Planta Daninha, v. 25, n. 2, p. 381-388, 2007

20. SPADOTTO, C. A. et al. Determinação do período crítico de prevenção da interferência de plantas daninhas na cultura de soja: uso do modelo "Broken-Stick". Planta Daninha, v. 12, n. 2, p. 59-62, 1994.

21. VARGAS, L. et al. Alteração das características biológicas dos biótipos de azevém (Lolium multiflorum) ocasionada pela resistência ao herbicida glyphosate. Planta Daninha, v. 23, n. 1, p. 153-160, 2005.

Recebido em 26/02/2009

Aceito em 19/05/2009 
